\title{
Mutational and clinical spectrum of Japanese patients with hereditary hemorrhagic telangiectasia
}

Kana Kitayama ${ }^{1}$, Tomoya Ishiguro ${ }^{2}$, Masaki Komiyama², Takayuki Morisaki ${ }^{3,4}$, Hiroko Morisaki ${ }^{5}$, Gaku Minase ${ }^{6}$, Kohei Hamanaka ${ }^{6}$, Satoko Miyatake ${ }^{6}$, Naomichi Matsumoto ${ }^{6}$, Masaru Kato $^{7}$, Toru Takahashi ${ }^{7}$ and Tohru Yorifuji ${ }^{1,7^{*}}$

\begin{abstract}
Background: Hereditary hemorrhagic telangiectasia $(H H T)$ is a dominantly inherited vascular disorder characterized by recurrent epistaxis, skin/mucocutaneous telangiectasia, and organ/visceral arteriovenous malformations (AVM). HHT is mostly caused by mutations either in the ENG or ACVRL1 genes, and there are regional differences in the breakdown of causative genes. The clinical presentation is also variable between populations suggesting the influence of environmental or genetic backgrounds. In this study, we report the largest series of mutational and clinical analyses for East Asians.
\end{abstract}

Methods: Using DNAs derived from peripheral blood leukocytes of 281 Japanese HHT patients from 150 families, all exons and exon-intron boundaries of the ENG, ACVRL1, and SMAD4 genes were sequenced either by Sanger sequencing or by the next-generation sequencing. Deletions/amplifications were analyzed by the multiplex ligation-dependent probe amplification analyses. Clinical information was obtained by chart review.

Results: In total, 80 and 59 pathogenic/likely pathogenic variants were identified in the ENG and ACVRL1 genes, respectively. No pathogenic variants were identified in the SMAD4 gene. In the ENG gene, the majority (60/80) of the pathogenic variants were private mutations unique to a single family, and the variants were widely distributed without any distinct hot spots. In the ACVRL 1 gene, the variants were more commonly found in exons 5-10 which encompasses the serine/threonine kinase domain. Of these, 25/59 variants were unique to a single family while those in exons 8-10 tended to be shared by multiple (2-7) families. Pulmonary and cerebral AVMs were more commonly found in ENG-HHT (69.1 vs. 14.4\%, 34.0 vs. 5.2\%) while hepatic AVM was more common in ACVRL1-HHT (31.5 vs. 73.2\%). Notable differences include an increased incidence of cerebral (34.0\% in ENG-HHT and 5.2\% in ACVRL 1-HHT), spinal (2.5\% in ENG-HHT and 1.0\% in ACVL1-HHT), and gastric AVM (13.0\% in ENG-HHT, 26.8\% in ACVRL1-HHT) in our cohort. Intrafamilial phenotypic heterogeneity not related to the age of examination was observed in $71.4 \%$ and $24.1 \%$ of ENG- and ACVRL 1-HHT, respectively.

\footnotetext{
*Correspondence: yorifuji.tohru.194@kyoto-u.jp

${ }^{1}$ Division of Pediatric Endocrinology and Metabolism, Children's Medical

Center, Osaka City General Hospital, 2-13-22 Miyakojima-hondori,

Miyakojima, Osaka 534-0021, Japan

Full list of author information is available at the end of the article
}

(c) The Author(s) 2021. Open Access This article is licensed under a Creative Commons Attribution 4.0 International License, which permits use, sharing, adaptation, distribution and reproduction in any medium or format, as long as you give appropriate credit to the original author(s) and the source, provide a link to the Creative Commons licence, and indicate if changes were made. The images or other third party material in this article are included in the article's Creative Commons licence, unless indicated otherwise in a credit line to the material. If material is not included in the article's Creative Commons licence and your intended use is not permitted by statutory regulation or exceeds the permitted use, you will need to obtain permission directly from the copyright holder. To view a copy of this licence, visit http://creativecommons.org/licenses/by/4.0/. The Creative Commons Public Domain Dedication waiver (http://creativeco mmons.org/publicdomain/zero/1.0/) applies to the data made available in this article, unless otherwise stated in a credit line to the data. 
Conclusions: In a large Japanese cohort, ENG-HHT was 1.35 times more common than ACVRL 1-HHT. The phenotypic presentations were similar to the previous reports although the cerebral, spinal, and gastric AVMs were more common.

Keywords: $E N G, A C V R L 1$, Hereditary hemorrhagic telangiectasia

\section{Background}

Hereditary hemorrhagic telangiectasia (HHT), also known as Osler-Weber-Rendu syndrome, is a dominantly-inherited genetic disorder affecting 1 in $5-8000$ individuals [1-4]. HHT is characterized by spontaneous epistaxis, multiple mucocutaneous telangiectasias, and arteriovenous shunts in various organs. The clinical diagnosis of HHT is made based on the Curaçao criteria [5]: (1) spontaneous, recurrent epistaxis; (2) multiple mucocutaneous telangiectasias at characteristic sites (lips, oral cavity, fingers, and nose); (3) visceral involvement including pulmonary, cerebral, hepatic, or gastrointestinal (GI) arteriovenous shunts; and (4) the presence of a first-degree relative with HHT. The diagnosis of HHT is 'definite' when $>3$ criteria are met, 'possible' when 2 criteria are met, and 'unlikely' when $<2$ criteria are met [5].

The majority (85-95\%) of HHT patients have mutations either in the endoglin $(E N G)$ gene (HHT1) or in the activin receptor-like kinase-1 (ACVRL1) gene (HHT2) [6-8]. Additionally, mutations in the SMAD family member 4 (SMAD4) gene cause a combined syndrome of HHT and juvenile polyposis [9] accounting for $\sim 2 \%$ of the HHT cases and, recently, mutations in the GDF2 gene on chromosome 10, coding for bone morphogenetic protein 9 (BMP9), has been implicated as a cause of HHT (HHT5) [8]. These genes are all part of the bone morphogenetic protein (BMP)/transforming growth factor (TGF $\beta$ ) signaling pathways and integral to angiogenesis [8] Pathogenic variants in any of these genes may disrupt the balance between pro- and antiangiogenic signals for normal vascular development, resulting in HHT. Other genetic loci have also been implicated by linkage analyses to two distinct loci on chromosomes 5 (HHT3) and 7 (HHT4) although no causative genes have been identified [10,11].

So far, more than 1000 different mutations have been identified as associated with ENG-HHT and ACVRL1HHT $[12,13]$. However, most of the large-scale studies have been conducted on Caucasians [1, 14-16], and only limited, relatively small studies have been reported for other populations [17-19]. Moreover, even within Caucasians, the reported mutational spectrum has been different depending on the countries so does the clinical presentation [14-16, 20].
In this study, we report the results of the largest mutational analyses for Asian HHT patients together with the detailed clinical presentation.

\section{Subjects and methods Subjects}

The study subjects were 281 (140 males, 141 females) Japanese patients from 150 families who were referred to Osaka City General Hospital during September 2010June 2021, diagnosed with HHT, and underwent mutational analysis. Osaka City General Hospital is the largest HHT center in Japan with patients referred from across Japan.

\section{Methods \\ Clinical diagnosis}

When patients with suspected HHT were referred to our institution, they routinely underwent the following diagnostic procedures: detailed past and family history taking, measurement of oxygen saturation, inspection for mucocutaneous telangiectasia, complete blood counts with differentials, blood chemistry, and electrolytes, followed by the diagnostic imaging including the brain, pulmonary, and liver vascular malformations. Specifically, for the brain imaging, non-contrast and contrast MR imaging including T1-, T2-, T2*-weighted, FLAIR, images and contrast-enhanced MR angiography at 1.5 or 3.0-T were performed. Additional routine imaging studies include dynamic, contrast-enhanced $\mathrm{CT}$ imaging of the liver (plain, early, and delayed phases), and axial contrast-enhanced images of the lung, spine, abdomen, and pelvis. The GI tract examination by the upper and lower tract fiberscope was performed only when severe anemia cannot be explained by the present epistaxis. When bleeding from the small intestine was suspected, capsule endoscopy was indicated.

Following these procedures, the probands from each family were diagnosed with definite/probable HHT by the Curaçao diagnostic criteria [5].

(Mutational analysis) Mutational analysis was proposed basically to all proband patients with the clinical diagnosis of HHT. Mutational analyses were also offered for selected family members including minors yet without a clinical diagnosis of HHT.

Using DNAs extracted from the peripheral blood leukocytes, all exons and exon-intron boundaries of the 
ENG, ACVR1, and SMAD4 genes were sequenced either by Sanger sequencing using the ABI PRISM3130xl Genetic Analyzer (ThermoFisher, Waltham, USA) or by next-generation sequencing using the Ion PGM system (ThermoFisher), HiSeq 2000, or HiSeq 2500 (Illumina, San Diego, USA). In addition, multiplex ligation-dependent probe amplification (MLPA) analyses were performed using the probemix P093 HHT/HPAH (MRC Holland, Amsterdam, Netherlands) to detect deletion/ amplification in the ENG and ACVR1 genes. The pathogenic significance of the identified variants was determined according to the criteria of the American College of Medical Genetics [21]. The SIFT (https://sift.bii.a-star. edu.sg/), Polyphen 2 (http://genetics.bwh.harvard.edu/ pph2/), and Combined Annotation-Dependent Depletion (CADD, https://cadd.gs.washington.edu/) programs were used for the determination of the pathogenicity scores. The clinical data were obtained by chart review.

The study protocol was approved by the Institutional Review Board at Osaka City General Hospital (No. 170850) and the study was performed under written informed consent from the patients or the guardians when appropriate.

\section{Results}

Detailed mutational and clinical data of all patients are listed in supplemental Table 1.

Table 1 shows the identified pathogenic (P)/likely pathogenic (LP) variants of the probands from each family. In total, 80 and $59 \mathrm{P} / \mathrm{LP}$ variants were identified in the ENG and ACVRL1 genes, respectively. No pathogenic variants were identified in the SMAD4 gene. Eleven probands with the diagnosis of definite/possible HHT by the Curaçao diagnostic criteria did not have any P/LP variants. However, two of them were found to have 5'untranslated region (UTR) variants in the ENG gene of unknown significance, $-79 \mathrm{C}>\mathrm{T}$ and $-33 \mathrm{~A}>\mathrm{G}$, respectively. Among the $80 \mathrm{P} / \mathrm{LP}$ variants in the ENG gene, 20 were novel, and, although not tested for all families, at least 3 were de novo variants. Similarly, among the 59 $\mathrm{P} / \mathrm{LP}$ variants in the $A C V R L 1$ gene, 9 were novel and at least one was a de novo variant.

Table 2 shows the details of the identified pathogenic variants. In the ENG gene, the majority (60/80) of the pathogenic variants were private mutations unique to a single family and the variants were widely distributed in exons 1-13 coding for the 5'-UTR and the extracellular domain of endoglin. In the ACVRL1 gene, as previously reported [3], the variants were more commonly found in exons 5-10 which encompasses the serine/threonine kinase domain. Again, the majority (25/59) of these variants were unique to a single family although those in exons $8-10$ tended to be shared by multiple $(2-7)$ families.

Table 3 shows the age-specific phenotypes of all ENGand ACVRL1-HHT patients. As the patients grow older, their chances of receiving definite/probable diagnosis increased, and, after age 40, almost all patients can be clinically diagnosed as definite HHT by the Curaçao criteria [5]. As previously reported, epistaxis was the most common symptom found in almost all patients with ENG- or ACVRL1-HHT after 12 years of age. Overall, organ or visceral AVMs were found in 84.6 and $79.3 \%$ of the patients with ENG- and ACVRL1-HHT, respectively. Pulmonary and brain AVMs were more common in ENG-HHT as compared with ACVRL1-HHT (69.1 vs. $14.4 \%, 34.0$ vs. $5.2 \%$ ) and identified earlier in life although the incidence of pulmonary AVM below 6 years of age (28.6\%) was lower as compared with that above 6 years of age (68.8-100\%). Hepatic AVM was more common in ACVRL1-HHT (31.5 vs $73.2 \%$ ) and identified relatively later in life although the incidence started to rise after

Table 1 Breakdown of identified mutations of the probands

\begin{tabular}{|c|c|c|c|c|}
\hline & ENG & ACVRL1 & SMAD4 & Not identified \\
\hline Number of probands with pathogenic variants & 80 & 59 & 0 & 11 \\
\hline Sex (male/female) & $46 / 34$ & $23 / 36$ & 0 & $4 / 7$ \\
\hline Novel variants & 20 & 9 & 0 & \\
\hline De novo variants & $3(3.8 \%)$ & $1(1.7 \%)$ & & \\
\hline \multicolumn{5}{|l|}{ Variant types } \\
\hline Missense & $23(28.8 \%)$ & $38(64.4 \%)$ & $0(0 \%)$ & \\
\hline Nonsense/frameshift & $28(35.0 \%)$ & $18(30.5 \%)$ & $0(0 \%)$ & \\
\hline Splice site & $20(25.0 \%)$ & $3(5.1 \%)$ & $0(0 \%)$ & \\
\hline Large deletion & $5(6.3 \%)$ & $0(0 \%)$ & $0(0 \%)$ & \\
\hline In-frame deletion of 12-18 bp & $3(3.8 \%)$ & & & \\
\hline $5^{\prime}-U T R$ & $1(1.3 \%)$ & & & \\
\hline
\end{tabular}

ENG endoglin, ACVRL1 activin A receptor like type 1, SMAD4 SMAD Family Member 4, UTR untranslated region 
Table 2 Details of the identified pathogenic/likely pathogenic variants

\begin{tabular}{|c|c|c|c|c|}
\hline Nucleotide change & Amino acid change & Exon & Previously reported? & $\begin{array}{l}\text { Number } \\
\text { of } \\
\text { families }\end{array}$ \\
\hline \multicolumn{5}{|l|}{ ENG } \\
\hline c. $-127 C>T$ & decreased translation & & No & 1 \\
\hline$c .67+1 G>A$ & splicing defects & & No & 1 \\
\hline C.97C > T & p.Gln33* & 2 & Yes & 1 \\
\hline c. $125 \mathrm{~T}>\mathrm{G}$ & p.Val42Gly & 2 & No & 1 \\
\hline c.132_133delTA & p.Thr45Hisfs & 2 & No & 1 \\
\hline c. $219 G>A$ & p.Thr73 = (skipping of exon 2) & 2 & No & 2 \\
\hline C.239T >C & p.Leu80Pro & 3 & No & 1 \\
\hline c. $277 \mathrm{C}>\mathrm{T}$ & p.Arg93* & 3 & Yes & 1 \\
\hline c.277delC & p.Arg93Glufs*9 & 3 & No & 1 \\
\hline c.319delC & p.Leu107Cys fs & 3 & No & 1 \\
\hline c. $357 C>G$ & p.Tyr120llefs*42 & 3 & No & 1 \\
\hline c. $360+1 G>C$ & splicing defects & & No & 1 \\
\hline$c .360+1 G>A$ & splicing defects & & No & 3 \\
\hline c.433delC & p.Gln145Argfs*18 & 4 & No & 1 \\
\hline c.461_462insG & p.lle156Hisfs & 4 & No & 1 \\
\hline c.478delG & p.Ala160Leufs*3 & 4 & No & 1 \\
\hline c. $494 C>A$ & p.Pr165His & 4 & No & 1 \\
\hline C. $497 \mathrm{~A}>\mathrm{C}$ & p.GIn166Pro & 4 & Yes & 2 \\
\hline C. $524-1 G>C$ & splicing defects & & No & 1 \\
\hline c.581_595del15b & p.Leu194_Pro198del5AA & 5 & No & 1 \\
\hline c.586 T > A & p.Trp196Arg & 5 & No & 1 \\
\hline c.611_628del18b & p.Val204_Leu209del & 5 & No & 1 \\
\hline C. $614 G>C$ & p.Arg205Pro & 5 & Yes & 1 \\
\hline c.647_658del & p.His215_Ala218del & 5 & No & 1 \\
\hline c.685delG & p.Ala229Profs*5 & 5 & No & 1 \\
\hline c. $760 C>T$ & p.Gln $254^{*}$ & 6 & No & 1 \\
\hline c.785 T >C & p.L262P & 6 & Yes & 1 \\
\hline$c .816+2 \mathrm{~T}>\mathrm{A}$ & splicing defects & & No & 3 \\
\hline c. $817-1 G>C$ & splicing defects & & No & 1 \\
\hline $\mathrm{c} .937 \mathrm{~T}>\mathrm{C}$ & p.Ser313Pro & 7 & No & 1 \\
\hline c. $944 \mathrm{~T}>\mathrm{A}$ & p.Val315Glu & 7 & No & 1 \\
\hline c.952-961del10b & p.Pro318Alafs & 7 & No & 1 \\
\hline c.965_966delTT & p.lle322Serfs*11 & 7 & No & 1 \\
\hline c. $991 \mathrm{G}>\mathrm{A}$ & p.Gly331Ser & 7 & Yes & 1 \\
\hline c.992-1G > A & splicing defects & & No & 1 \\
\hline c. $1087 \mathrm{~T}>\mathrm{A}$ & p.Cys363Ser & 8 & Yes & 1 \\
\hline c. $1089 \mathrm{~T}>\mathrm{G}$ & p.Cys363Trp & 8 & No & 1 \\
\hline C. $1103 \mathrm{~T}>\mathrm{C}$ & p.Met368Thr & 8 & Yes & 2 \\
\hline C.1109T>C & p.Leu370Pro & 8 & Yes & 1 \\
\hline C.1134G > A & p.Ala378 = (splicing defect) & 8 & Yes & 1 \\
\hline C. $1134+1 G>C$ & splicing defects & & No & 1 \\
\hline C. $1134+1$ delG & splicing defects & & No & 1 \\
\hline c.1140_1141insCTACCCAGCATTTG & p.Lys381Leufs*5 & 9 & No & 1 \\
\hline c.1160_1173delTGACCTTCTGGGAC & p.Leu387Profs $* 4$ & 9 & No & 1 \\
\hline C.1169G > A & p.Trp390* & 9 & Yes & 1 \\
\hline C. $1181 G>A$ & p.Cys394Tyr & 9 & Yes & 1 \\
\hline c.1195delA & p.Arg399Glyfs*22 & 9 & No & 1 \\
\hline
\end{tabular}


Table 2 (continued)

\begin{tabular}{|c|c|c|c|c|}
\hline Nucleotide change & Amino acid change & Exon & Previously reported? & $\begin{array}{l}\text { Number } \\
\text { of } \\
\text { families }\end{array}$ \\
\hline c.1209_1210insTT & p.Val404Leufs*18 & 9 & No & 1 \\
\hline c. $1235 G>A$ & p.Cys412Tyr & 9 & Yes & 2 \\
\hline c. $1268 A>G$ & p.Asn423Ser & 9 & Yes & 1 \\
\hline c. $1306 C>T$ & p.Gln436* & 10 & Yes & 1 \\
\hline c. $1311+2 T>C$ & splicing defects & & No & 3 \\
\hline c.1319T>C & p.Val440Ala & 11 & No & 1 \\
\hline c.1346_1347delCT & p.Ser449Phefs*51 & 11 & No & 1 \\
\hline c. $1411 C>T$ & p.G $\ln 471^{*}$ & 11 & Yes & 1 \\
\hline c. $1429-2 A>G$ & splicing defects & & No & 1 \\
\hline c. $1465 C>T$ & p.G $\ln 489^{*}$ & 12 & No & 1 \\
\hline c. $1513 G>T$ & p.Glu505* & 12 & Yes & 1 \\
\hline c. $1517 \mathrm{~T}>\mathrm{C}$ & p.Leu506Pro & 12 & Yes & 2 \\
\hline c.1649_1650insAC & p.Val551Argfs*2 & 12 & No & 1 \\
\hline c.1672_1684del13b & p.Gly558fs & 12 & No & 1 \\
\hline c.1675_1678delTCTC & p.Ser559Lysfs*13 & 12 & No & 1 \\
\hline c.1687delG & p.Glu563Lys fs & 13 & No & 1 \\
\hline del exons 3-8 & & $3-8$ & No & 1 \\
\hline del exons 3-8 & & $3-8$ & No & 1 \\
\hline del exons 3-14 & & $3-14$ & No & 1 \\
\hline del exons 13-14 & & $13-14$ & No & 1 \\
\hline del exons 9-14 & & $9-14$ & No & 1 \\
\hline \multicolumn{5}{|l|}{ ACVRL1 } \\
\hline c.90_102delGCTGGTGACCTGC & p.Leu31Argfs*19 & 3 & No & 2 \\
\hline c.95T $>$ A & p.Val32Glu & 3 & No & 1 \\
\hline c.203delG & p.Gly68Alafs*54 & 3 & No & 1 \\
\hline c. $270 C>G$ & p.Cys90Trp & 3 & Yes & 1 \\
\hline c. $352 C>T$ & p.Gln118* & 4 & Yes & 1 \\
\hline c. $430 C>T$ & p.Arg144* & 4 & Yes & 1 \\
\hline c. $448 \mathrm{C}>\mathrm{T}$ & p.Q150* & 4 & Yes & 2 \\
\hline c.480_486dupCAGTCTC & p.lle163fs & 4 & No & 1 \\
\hline C. $505 C>T$ & p.Gln169* & 4 & Yes & 1 \\
\hline$c .525+1 G>C$ & splicing defects & & No & 1 \\
\hline c. $525+1$ delG & splicing defects & & Yes & 1 \\
\hline $\mathrm{c} .598 \mathrm{C}>\mathrm{G}$ & p.Arg200Gly & 5 & Yes & 3 \\
\hline c. $614 \mathrm{~T}>\mathrm{G}$ & p.Val205Gly & 5 & Yes & 2 \\
\hline c. $772+3 \_772+4$ dupAA & unknown, splicing defects? & & No & 1 \\
\hline c. $830 C>G$ & p.Thr277Arg & 7 & No & 1 \\
\hline c. $839 A>G$ & p.His280Arg & 7 & Yes & 2 \\
\hline c.899 T >C & p.Leu300Pro & 7 & No & 1 \\
\hline c.926G $>\mathrm{T}$ & p.Gly309Val & 7 & Yes & 1 \\
\hline c. $956 \mathrm{G}>\mathrm{T}$ & p.Gly319Val & 7 & No & 1 \\
\hline c.969_970insA & p.Pro324Thr fs*73 & 7 & No & 1 \\
\hline c. $982 C>T$ & p.His328Tyr & 7 & Yes & 1 \\
\hline C. $982 C>A$ & p.His328Asn & 7 & No & 1 \\
\hline c. $994 \mathrm{~A}>\mathrm{T}$ & p.Lys332* & 7 & Yes* & 1 \\
\hline c. $1044 C>G$ & p.Asp348Glu & 7 & No & 1 \\
\hline c. $1069 C>T$ & p.G $\ln 357^{*}$ & 8 & Yes & 1 \\
\hline c. $1120 C>T$ & p.Arg374Trp & 8 & Yes & 1 \\
\hline
\end{tabular}


Table 2 (continued)

\begin{tabular}{|c|c|c|c|c|}
\hline Nucleotide change & Amino acid change & Exon & Previously reported? & $\begin{array}{l}\text { Number } \\
\text { of } \\
\text { families }\end{array}$ \\
\hline c. $1121 \mathrm{G}>\mathrm{A}$ & p.Arg374Gln & 8 & Yes & 2 \\
\hline c. $1132 C>T$ & p.Pro378Ser & 8 & Yes & 1 \\
\hline c. $1231 C>T$ & p.Arg411Trp & 8 & Yes & 3 \\
\hline c. $1232 \mathrm{G}>\mathrm{A}$ & p.Arg411Gln & 8 & Yes & 4 \\
\hline c. $1271 C>T$ & p.Pro424Leu & 9 & Yes & 1 \\
\hline c. $1327 C>T$ & p.Cys443Arg & 9 & No & 1 \\
\hline c. $1345 C>G$ & p.Pro449Ala & 9 & No & 2 \\
\hline c. $1412 \mathrm{G}>\mathrm{A}$ & p.Cys471Tyr & 10 & No & 2 \\
\hline c. $1435 C>T$ & p.Arg479* & 10 & Yes & 7 \\
\hline c. $1436 \mathrm{G}>\mathrm{A}$ & p.Arg479GIn & 10 & Yes & 1 \\
\hline c. $1451 G>A$ & p.Arg484Gln & 10 & Yes & 3 \\
\hline
\end{tabular}

Table 3 Age-related phenotypes of ENG and ACVRL 1-HHT patients

\begin{tabular}{|c|c|c|c|c|c|c|c|c|c|c|c|c|c|c|}
\hline & ENG & & & & & & & ACVRL 1 & & & & & & \\
\hline Age (years) & $0-5$ & $6-11$ & $12-19$ & $20-39$ & $40-59$ & $60-$ & Total (\%) & $0-5$ & $6-11$ & $12-19$ & $20-39$ & $40-59$ & $60-$ & Total (\%) \\
\hline No of patients & 14 & 16 & 10 & 43 & 52 & 27 & 162 & 3 & 3 & 6 & 21 & 39 & 25 & 97 \\
\hline \multicolumn{15}{|l|}{ Curaçao criteria $(N=259)$} \\
\hline Definite & 6 & 11 & 8 & 38 & 51 & 27 & $141(87.0)$ & 1 & 1 & 4 & 15 & 39 & 25 & $85(87.6)$ \\
\hline Probable & 3 & 4 & 2 & 5 & 1 & 0 & $15(9.3)$ & 1 & 1 & 2 & 4 & 0 & 0 & $8(8.2)$ \\
\hline Unlikely & 5 & 1 & 0 & 0 & 0 & 0 & $6(3.7)$ & 1 & 1 & 0 & 2 & 0 & 0 & $4(4.1)$ \\
\hline \multicolumn{15}{|l|}{ Clinical presentation } \\
\hline Epistaxis $(\mathrm{N}=259)$ & 9 & 14 & 10 & 43 & 52 & 28 & $156(96.3)$ & 1 & 2 & 6 & 19 & 39 & 25 & $92(94.8)$ \\
\hline Telangiectasia $(\mathrm{N}=259)$ & 1 & 5 & 8 & 30 & 45 & 27 & $116(71.6)$ & 0 & 0 & 3 & 11 & 39 & 25 & $78(80.4)$ \\
\hline AVMs of organs $(\mathrm{N}=252)$ & 7 & 13 & 10 & 35 & 47 & 25 & $137(84.6)$ & 0 & 1 & 2 & 14 & 36 & 24 & $77(79.3)$ \\
\hline Pulmonary $(\mathrm{N}=251)$ & 4 & 11 & 10 & 32 & 37 & 18 & $112(69.1)$ & 0 & 1 & 0 & 5 & 6 & 2 & $14(14.4)$ \\
\hline Brain $(N=245)$ & 5 & 9 & 5 & 14 & 12 & 10 & $55(34.0)$ & 0 & 0 & 1 & 1 & 3 & 0 & $5(5.2)$ \\
\hline Hepatic $(N=199)$ & 0 & 1 & 2 & 9 & 20 & 19 & $51(31.5)$ & 0 & 1 & 2 & 12 & 34 & 22 & $71(73.2)$ \\
\hline Spinal $(N=102)$ & 0 & 2 & 0 & 0 & 1 & 1 & $4(2.5)$ & 0 & 0 & 0 & 0 & 1 & 0 & $1(1.0)$ \\
\hline Gl tract $(\mathrm{N}=97)$ & 0 & 0 & 0 & 1 & 11 & 12 & $24(14.8)$ & 0 & 0 & 0 & 0 & 14 & 12 & $26(26.8)$ \\
\hline Esophageal & 0 & 0 & 0 & 0 & 0 & 1 & $1(0.6)$ & 0 & 0 & 0 & 0 & 1 & 0 & $1(1.0)$ \\
\hline Gastric & 0 & 0 & 0 & 0 & 10 & 11 & $21(13.0)$ & 0 & 0 & 0 & 0 & 14 & 12 & $26(26.8)$ \\
\hline Duodenal & 0 & 0 & 0 & 1 & 2 & 2 & $5(3.1)$ & 0 & 0 & 0 & 0 & 3 & 2 & $5(5.2)$ \\
\hline Colonic & 0 & 0 & 0 & 0 & 2 & 5 & $7(4.3)$ & 0 & 0 & 0 & 0 & 3 & 1 & $4(4.1)$ \\
\hline
\end{tabular}

6 years of age. Interestingly, in contrast with the previous reports, we observed an increased incidence of cerebral AVM (34.0\% in ENG-HHT and 5.2\% in ACVRL1-HHT) in our cohort as opposed to the previously reported incidence at $8-20.9 \%$ in ENG-HHT and 0-2.4\% in ACVRL1HHT [1, 4, 22, 23]. Spinal AVM was also found more commonly at $2.5 \%$ and $1.0 \%$ in ENG- and ACVRL1-HHT, respectively. Additionally, the incidence of gastric AVM (13.0\% in ENG-HHT, 26.8\% in ACVRL1-HHT) was higher as compared with that of duodenal AVM (3.1\% in ENG-HHT, $5.2 \%$ in ACVRL1-HHT). This is in contrast with the previous studies reporting a higher incidence of intestinal AVM among those with GI-AVM [24-26].

For 80 ENG-HHT and 59 ACVRL1-HHT families, detailed phenotype information of multiple family members was available (Additional file 1: Table S1). In 30 (71.4\%) ENG-HHT families, obvious intrafamilial phenotypic heterogeneity not related to the age of examination was observed. The differences were mostly manifested as the difference in the site of organ AVM between individuals. In the $A C V R L 1-\mathrm{HHT}$ families, the incidence of intrafamilial phenotypic heterogeneity was lower, found 
in 7 (24.1\%) families. The intrafamilial heterogeneity of organ AVM was found similarly across all organ AVMs.

\section{Discussion}

In our cohort of Japanese patients, the ENG mutations were dominant (ENG/ACVRL1 ratio at 1.35) although the difference was smaller as compared with our own previous smaller series [19]. Previous reports showed a considerable difference in the incidence of $E N G$ - vs ACVRL1-HHT with the ENG dominance in the US (ENG/ACVRL1 at 1.58) [27], Netherlands (3.40) [17], Denmark (4.05) [15], and Korea (1.47) [17] as opposed to the ACVRL1 dominance in France and Italy (0.37) [28], Germany (0.89) [29], and China (0.41) [18]. The founder effects could be one of the explanations for these differences although it is unclear whether the previously identified, small-sized founder effects could account for all these differences [30].

Overall, the breakdown of mutation types in our series was similar to that of previous reports for both the ENG and ACVRL1 genes (Table 1) [3, 15, 22]. Variants in the $E N G$ gene were distributed throughout the gene with no obvious hot spots while mutations were more frequently found in the region spanning the serine/threonine kinase domain of the ACVRL1 gene (Table 2). Also, as previously reported, the incidence of null mutations in the ENG gene was higher as compared with that of the $A C V R L 1$ gene [3].

Clinical features were mostly similar to those reported for other populations with an increased incidence of pulmonary and cerebral AVMs in ENG-HHT, and of hepatic AVM in ACVRL1-HHT [1, 2, 4, 19, 31]. Notable differences, however, include an increased incidence of cerebral, spinal, and gastric AVMs in our cohort.

Studies have reported a considerable difference in the incidence of various organ AVMs in those with the same causative genes $[2,3,32]$. There are also phenotypic differences even within the same families as shown in the current study. These differences likely reflect the difference in the environmental factors, ascertainment biases, or the difference in the other genetic backgrounds acting as the second hits for the development of symptoms [8]. Previous reports on the presentation of HHT in monozygotic twins showed that the presentations are similar but different supporting the influence of both genetic and environmental contribution for the development of symptoms [33-35].

The reason why the cerebral, spinal, and gastric AVMs were more common in our series is not clear. It has been reported that the incidence of cerebral hemorrhage is twofold higher in Japanese as compared with that of Caucasians [36]. Similarly, the incidence of gastric cancer is markedly increased in east Asian countries including
Japan compared with that in other areas of the world [37]. The increased incidence of cerebral and gastric AVMs might have common backgrounds of these organ vulnerabilities.

\section{Conclusions}

The largest mutational and clinical study in Japanese HHT showed an ENG-HHT dominance over ACVRL1HHT. The mutational spectrum was similar to those reported for other populations although the cerebral, spinal, and gastric AVMs were more commonly seen.

\section{Abbreviations \\ HHT: Hereditary hemorrhagic telangiectasia; ENG: Endoglin; ACVRL1: Activin A receptor like type 1; SMAD4: SMAD Family Member 4; AVM: Arteriovenous malformation; Gl: Gastrointestinal; P/LP: Pathogenic/likely pathogenic.}

\section{Supplementary Information}

The online version contains supplementary material available at https://doi. org/10.1186/s12920-021-01139-y.

Additional file 1: Detailed mutational and clinical data of all patients.

\section{Acknowledgements}

We thank the HHT families for their participation in the study.

\section{Authors' contributions}

TY and MK conceived and supervised the whole project; KK analyzed the whole data and wrote the manuscript; TI and MK did clinical workups; TM, HM, $\mathrm{GM}, \mathrm{KH}, \mathrm{SM}, \mathrm{NM}, \mathrm{MK}, \mathrm{TT}$, and TY did mutational analyses and annotated the data. All authors read and approved the final manuscript.

\section{Funding}

This work was supported by Japan Society for the Promotion of Science under grant numbers 18K07895 (T. Yorifuji), 20 K07907 (S. Miyatake), 16 K09486 (T. Morisaki); Japan Agency for Medical Research and Development (AMED) under grant numbers 21 ek0109486, 21ek0109549, and 21ek0109493 (N. Matsumoto); the Ministry of Health, Labour and Welfare of Japan under grant numbers 20141508A, 25-2-3 (T. Morisaki).

Availability of data and materials

Detailed mutational and clinical data of all patients are submitted as supplemental Table 1.

\section{Declarations}

\section{Ethics approval and consent to participate}

The study protocol was approved by the Institutional Review Board at Osaka City General Hospital (No. 170850) and the study was performed under written informed consent from the patients or the guardians when appropriate. All methods were carried out in accordance with relevant guidelines and regulations.

\section{Consent for publication}

Not applicable.

\section{Competing interests}

The authors declare that they have no competing interests.

\section{Author details}

${ }^{1}$ Division of Pediatric Endocrinology and Metabolism, Children's Medical Center, Osaka City General Hospital, 2-13-22 Miyakojima-hondori, Miyakojima, 
Osaka 534-0021, Japan. ${ }^{2}$ Department of Neuro-Intervention, Osaka City General Hospital, Osaka, Japan. ${ }^{3}$ Division of Molecular Pathology, The Institute of Medical Science, The University of Tokyo, Tokyo, Japan. ${ }^{4}$ Department of Bioscience and Genetics, National Cerebral and Cardiovascular Center, Osaka, Japan. ${ }^{5}$ Department of Medical Genetics, Sakakibara Heart Institute, Tokyo, Japan. ${ }^{6}$ Department of Human Genetics, Yokohama City University Graduate School of Medicine, Kanagawa, Japan. ${ }^{7}$ Department of Genetic Medicine, Osaka City General Hospital, Osaka, Japan.

Received: 11 October 2021 Accepted: 29 November 2021

Published online: 06 December 2021

\section{References}

1. Kühnel T. Hereditary hemorrhagic telangiectasia. Otolaryngol Clin North Am. 2018;51:237-54.

2. Kritharis A. Hereditary hemorrhagic telangiectasia: diagnosis and management from the hematologist's perspective. Haematologica. 2018;103:1433-43.

3. Abdalla SA, Letarte M, et al. Hereditary haemorrhagic telangiectasia: current views on genetics and mechanisms of disease. J Med Genet. 2006;43:97-110.

4. de Gussem EM, Kroon S, Hosman AE, Kelder JC, Post MC, Snijder RJ et al. Hereditary Hemorrhagic Telangiectasia (HHT) and Survival: the importance of systematic screening and treatment in $\mathrm{HHT}$ centers of excellence. J Clin Med. 2020;9:3581.

5. Shovlin CL, Guttmacher AE, Buscarini E, Faughnan ME, Hyland RH, Westermann CJ, et al. Diagnostic criteria for hereditary hemorrhagic telangiectasia (Rendu-Osler-Weber syndrome). Am J Med Genet. 2000:91:66-7.

6. Sadick H, Hage J, Goessler U, Stern-Straeter J, Riedel F, Hoermann K, et al. Mutation analysis of "Endoglin" and "Activin receptor-like kinase" genes in German patients with hereditary hemorrhagic telangiectasia and the value of rapid genotyping using an allele-specific PCR-technique. BMC Med Genet. 2009;10:53.

7. Saito T, Bokhove M, Croci R, Zamora-Caballero S, Han L, Letarte M, et al. Structural basis of the human endoglin-BMP9 interaction: insights into BMP signaling and HHT1. Cell Rep. 2017;19:1917-28.

8. Bernabeu C, Bayrak-Toydemir P, McDonald J, Letarte M, et al. Potential second-hits in hereditary hemorrhagic telangiectasia. J Clin Med. 2020;9:3571.

9. Gallione CJ, Repetto GM, Legius E, Rustgi AK, Schelley SL, Tejpar S, et al. A combined syndrome of juvenile polyposis and hereditary haemorrhagic telangiectasia associated with mutations in MADH4 (SMAD4). Lancet. 2004;363:852-9.

10. Cole SG, Begbie ME, Wallace GM, Shovlin CL, et al. A new locus for hereditary haemorrhagic telangiectasia (HHT3) maps to chromosome 5. J Med Genet. 2005;42:577-82.

11. Bayrak-Toydemir P, McDonald J, Akarsu N, Toydemir RM, Calderon F, Tuncali T, et al. A fourth locus for hereditary hemorrhagic telangiectasia maps to chromosome 7. Am J Med Genet A. 2006;140:2155-62.

12. University of Utah ARUP Scientific Resource for Research and Education: ENG Database. http://arup.utah.edu/database/ENG/ENG_display. php. Accessed 27 Aug 2021.

13. University of Utah ARUP Scientific Resource for Research and Education: ACVRL1 Database. http://arup.utah.edu/database/ACVRL1/ ACVRL1_display.php. Accessed 27 Aug 2021.

14. Giraud S, Bardel C, Dupuis-Girod S, Carette MF, Gilbert-Dussardier B, Riviere $S$, et al. Sequence variations of ACVRL1 play a critical role in hepatic vascular malformations in hereditary hemorrhagic telangiectasia. Orphanet J Rare Dis. 2020;15:254

15. Tørring PM, Brusgaard K, Ousager LB, Andersen PE, Kjeldsen AD, et al. National mutation study among Danish patients with hereditary haemorrhagic telangiectasia. Clin Genet. 2014;86:123-33.

16. Letteboer TG, Mager JJ, Snijder RJ, Koeleman BP, Lindhout D, Ploos van Amstel JK, et al. Genotype-phenotype relationship in hereditary haemorrhagic telangiectasia. J Med Genet. 2006;43:371-7.

17. Kim D, Seo E-J, Song YS, Suh CH, Kim JW, Kim DJ, Suh DC, et al. Current status of clinical diagnosis and genetic analysis of hereditary hemorrhagic telangiectasia in South Korea: multicenter case series and a systematic review. Neurointervention. 2019;14:91-8.

18. Zhao $Y$, Zhang $Y$, Wang $X$, Zhang $L$, et al. Variant analysis in Chinese families with hereditary hemorrhagic telangiectasia. Mol Genet Genomic Med. 2019;7:e893.

19. Komiyama M, Ishiguro T, Yamada O, Morisaki H, Morisaki T, et al. Hereditary hemorrhagic telangiectasia in Japanese patients. J Hum Genet. 2014;59:37-41.

20. Pahl KS, Choudhury A, Wusik K, Hammill A, White A, Henderson K, et al. Applicability of the curaçao criteria for the diagnosis of hereditary hemorrhagic telangiectasia in the pediatric population. J Pediatr. 2018;197:207-13.

21. Richards S, Aziz N, Bale S, Bick D, Das S, Gastier-Foster J, et al. Standards and guidelines for the interpretation of sequence variants: a joint consensus recommendation of the American College of Medical Genetics and Genomics and the Association for Molecular Pathology. Guideline Genet Med. 2015;17:405-24.

22. Sabbà C, Pasculli G, Lenato GM, Suppressa P, Lastella P, Memeo M, et al. Hereditary hemorrhagic telangiectasia: clinical features in ENG and ALK1 mutation carriers. J Thromb Haemost. 2007;5:1149-57.

23. Kroon S, Snijder RJ, Faughnan ME, Mager HJ, et al. Systematic screening in hereditary hemorrhagic telangiectasia: a review. Curr Opin Pulm Med. 2018;24:260-8.

24. Canzonieri C, Centenara L, Ornati F, Pagella F, Matti E, Alvisi C, et al. Endoscopic evaluation of gastrointestinal tract in patients with hereditary hemorrhagic telangiectasia and correlation with their genotypes. Genet Med. 2014;16:3-10.

25. Jackson SB, Villano NP, Benhammou JN, Lewis M, Pisegna JR, Padua $D$, et al. Gastrointestinal manifestations of hereditary hemorrhagic telangiectasia (HHT): a systematic review of the literature. Dig Dis Sci. 2017;62:2623-30

26. Grève E, Moussata D, Gaudin JL, Lapalus MG, Giraud S, Dupuis-Girod $\mathrm{S}$, et al. High diagnostic and clinical impact of small-bowel capsule endoscopy in patients with hereditary hemorrhagic telangiectasia with overt digestive bleeding and/or severe anemia. Gastrointest Endosc. 2010;71:760-7.

27. Beckman JD, Li Q, Hester ST, Leitner O, Smith KL, Kasthuri RS, et al. Integration of clinical parameters, genotype and epistaxis severity score to guide treatment for hereditary hemorrhagic telangiectasia associated bleeding. Orphanet J Rare Dis. 2020;15:185.

28. Lesca G, Olivieri C, Burnichon N, Pagella F, Carette MF, Gilbert-Dussardier B, et al. Genotype-phenotype correlations in hereditary hemorrhagic telangiectasia: data from the French-Italian HHT network. Genet Med. 2007;9:14-22.

29. Schulte C, Geisthoff U, Lux A, Kupkal S, Zenner HP, Blin N, et al. High frequency of ENG and ALK1/ACVRL1 mutations in German HHT patients. Hum Mutat. 2005;25:595

30. Major T, Gindele R, Balogh G, Bárdossy P, Bereczky Z. et al. Founder effects in hereditary hemorrhagic telangiectasia. J Clin Med. 2021;10:1682.

31. Mutize TT, Seedat RY, van Amstel JKP, Mager JJ, Brown SC, Gebremariam $F$, et al. The clinical and genetic features of hereditary haemorrhagic telangiectasia (HHT) in central South Africa-three novel pathogenic variants. Mol Biol Rep. 2020;47:9967-72.

32. Goulielmos GN, Eliopoulos E, Karatzanis A, Zervou MI, Fountakis E, et al. Mutational analysis mapping on the molecular structure of the ACVRL1 protein and implications for Rendu-Osler-Weber (ROW). Int J New Innov Eng Technol. 2016;2:32-6.

33. Rattani A, Dewan MC, Hannig V, Naftel RP, Wellons JC 3rd, Jordan LC, et al. Cerebral hemorrhage in monozygotic twins with hereditary hemorrhagic telangiectasia: case report and hemorrhagic risk evaluation. J Neurosurg Pediatr. 2017;20:164-9.

34. Lesser BA, Wendt D, Miks VM, Norum RA, et al. Identical twins with hereditary hemorrhagic telangiectasia concordant for cerebrovascular arteriovenous malformations. Am J Med. 1986;81:931-4.

35. Komiyama M, Ishiguro T, Tereda A. Monozygotic twins with endoglin mutations. Angiogenesis. 2019;22:614.

36. Suzuki K, Izumi M. The incidence of hemorrhagic stroke in Japan is twice compared with western countries: the Akita stroke registry. Neurol Sci. 2015;36:155-60. 
37. Wong MCS, Huang J, Chan PSF, Choi P, Lao XQ, Chan SM, et al. Global incidence and mortality of gastric cancer, 1980-2018. JAMA Netw Open. 2021;4:e2118457.

\section{Publisher's Note}

Springer Nature remains neutral with regard to jurisdictional claims in published maps and institutional affiliations.

- fast, convenient online submission

- thorough peer review by experienced researchers in your field

- rapid publication on acceptance

- support for research data, including large and complex data types

- gold Open Access which fosters wider collaboration and increased citations

- maximum visibility for your research: over $100 \mathrm{M}$ website views per year

At BMC, research is always in progress.

Learn more biomedcentral.com/submissions 